Wayne State University

DigitalCommons@WayneState

Working Group on Interlocal Services Cooperation

Political Science

$10-6-2007$

\title{
Outsourcing in U.S. Cities, Ambulances and Elderly Voters
}

Matthew J. Holian

The Ohio State University, matthew.holian@sjsu.edu

\section{Recommended Citation}

Holian, Matthew J., "Outsourcing in U.S. Cities, Ambulances and Elderly Voters" (2007). Working Group on Interlocal Services Cooperation. Paper 39.

http://digitalcommons.wayne.edu/interlocal_coop/39 


\title{
Outsourcing in U.S. Cities, Ambulances and Elderly Voters
}

\author{
Matt Holian*
}

October 6, 2007

\begin{abstract}
Many of the largest cities in the United States outsource emergency medical services. This paper develops a political economy model of city service provision. Empirical analysis of emergency ambulances in the 200 largest U.S. cities finds that a number of variables are significant determinants of ambluance outsourcing, including the fraction of a city's voters over the age of 65 . This finding provides evidence that interest-group politics are important, and suggests a particular shape of the contracting cost curve. JEL codes: D23, D73, H11, H40, L33.
\end{abstract}

\section{Introduction}

How will aging baby boomers affect the scope of government? Over the twenty year period from 2010 to 2030, the percent of the population age 65 or older is projected to increase by more than half. ${ }^{1}$ In addition, it is likely that the elderly as a group enjoy non-trivial influence on policy. ${ }^{2}$ This article explores how age and other

*Department of Economics, The Ohio State University, 410 Arps Hall, 1945 N. High Street, Columbus OH 43210. e-mail: holian.5@osu.edu, web: www.mattholian.com. Special thanks are due to Don Haurin and Massimo Morelli (co-advisors), and also to Gene Mumy and Trevor Brown, with no implications. Thanks also to helpful comments from audiences at Ohio State (Columbus, 06), EITM V (Ann Arbor, 06), the Public Choice Societies (Amsterdam, 07), and BGSU (Bowling Green, 07).

${ }^{1}$ By 2010 approximately thirteen percent of the U.S. population will be age 65 or older. This figure is expected to rise to twenty percent by 2030. (Federal Interagency Forum on Aging-Related Statistics, "Older Americans 2004: Key Indicators of Well-Being." Washington, DC: U.S. Government Printing Office. November 2004.)

${ }^{2}$ Several studies provide evidence that the elderly are able to successfully target spending towards their preferences. Poterba (1997, 1998) and Brunner and Balsdon (2004) find a negative empirical correlation between public school spending and high numbers of elderly voters. Campbell (2003) explores the actual processes by which elderly achieve their policy objectives. 
characteristics of the electorate affect local government leaders' decision of whether or not to outsource public service provision, using data on emergency ambulances in the 200 largest U.S. cities.

This chapter also models the outsourcing question by viewing governments as firms, and looks by analogy to the boundary of the firm problem from industrial organization (Coase 1937). A number of both positive and normative models of public service delivery mode have been introduced in the modern branch of this literature; however there still is no agreed upon political theory of the firm model. ${ }^{3}$ The present paper extends the probabilistic voting model by building in transaction cost considerations, using a cost framework similar to that of Levin and Tadelis (2007), however with a wider parameter space of the contracting cost curve. This difference yields a number of new predictions coming from the model. These predictions are put to the test in the empirical section.

The empirical section of this paper focuses on cross-city effects, as opposed to cross-service factors, and focuses on a single public service, emergency ambulance service. While this single-service focus may appear limiting, it actually permits exploring topics that other studies of local government service contracting have been unable to pursue. Perhaps most important among these topics is the influence of interest groups. The elderly are a group for whom emergency ambulance service is important; this is intuitive, and it also has been documented that the elderly use emergency ambulances more than other groups. ${ }^{4}$ Another benefit of the single-service focus is the ability to better control for specific institutional details of the emergency ambulance service setting.

Emergency ambulance service is the transport component of emergency medical service (EMS). These are the types of ambulances that respond to "911" calls in the United States, or "112" calls in the European Union. This particular service exhibits great variation across cities in whether it is made by the city in house or outsourced; in the sample presented here, the service is outsourced somewhat more than half the time. Frequent outsourcing of emergency ambulances is in sharp contrast to the other core public safety services (policing and fire suppression) which are seldom outsourced. Also, the ambulance data used in this study allows for a more representative sample of cities. Previous studies used a sample of cities that are over represented by ones with the council-manager form of government. ${ }^{5}$

The summary of the theoretical model is as follows. Two political candidates compete for votes and heterogenous citizens vote for the candidate that promises them higher utility. The candidate that is elected has two technologies available to

\footnotetext{
${ }^{3}$ Examples of formal theory include Hart, Shleifer and Vishny (1997), Boycko, Shleifer and Vishny (1995) and Laffont and Tirole (1993). Related empirical work includes Lopez-de-Silanes, Shleifer and Vishny (1997), Levin and Tadelis (2007), and others; see reviews and references in Hirsch (1995), Mueller (2003), Gerber et al. (2004) and Brown and Potoski (2003).

${ }^{4}$ For evidence of a positive correlation between use and age, see Gerson and Skvarch (1982) and Downing and Wilson (2005).

${ }^{5}$ Brown and Potoski "Learning from experience"
} 
provide the public good: in-house ("make") technology and outsource ("buy") technology. Candidates anticipate the available technologies and without any primitive preference for mode, choose as a platform the level of service and mode of provision that maximizes their vote share; thus, service level and mode are determined jointly. In this setting, when groups of individuals have heterogenous tastes for the public good, demographic shifts can cause the platform that politicians run on to change. If the public good-loving group increases in size, politician's platforms increase with respect to service level. ${ }^{6}$ An increase in service level, in turn, causes the likelihood of outsourcing to either increase, decrease, decrease at first and then increase (Ushaped), or increase at first and then decrease (inverted U-shaped), depending on the contracting cost curve shape assumption. In addition to the two hypotheses always outsource and never outsource, the model generates four additional hypotheses for how demographic variation affects outsourcing. Results from the empirical section will help to test among the hypotheses.

The empirical section uses survey data on emergency ambulance provision in the 200 largest U.S. cities, conducted in 1990 and 2000. This data, combined with Census data of the basic demographic variables in the model, are used in the baseline regressions. The full empirical specification also includes data on partisan voting outcomes, labor market conditions, state legal institutions, and several other variables. Among the empirical findings for ambulances are that: public/private wage ratios are positively correlated to outsourcing likelihood, cities that are in Republican-leaning counties are more likely to outsource, and while most state laws related to city governance do not affect ambulance outsourcing, the presence of laws that forbid cities from short-term borrowing, and institutional arrangements where states rather than cities have responsilibity for assessing the value of residential property for taxation purposes, are both positively correlated with outsourcing. Average housing value, and especially population are also shown to be significant predictors of ambulance outsourcing. Also, the empirical section finds suggestive evidence that differences exist between how council-manager and mayor-council forms of government respond to political pressure.

The main correlation of interest, however, is between the percent of city's voting age population that is elderly and ambulance outsourcing. The results show an inverted U-shaped correlation. This finding is significant in both years and holds up in both the baseline and full empirical specifications. The inverted U-shaped correlation implies the following two features for an urban politics theory of the firm: First, the variable costs of contracting are convex. As politicians contract for higher levels of the public service in order to attract the votes of the elderly, contracting costs rise at an increasing rate, causing the costs of outsourcing to eventually surpass the costs of in-house provision. This finding provides support for one of Levin and Tadelis' (2007)

\footnotetext{
${ }^{6}$ To be more precise, an increase in the size of the public good-loving group causes service level to increase as long as this group's tax base is not too small. This insight is clarified in the next section.
} 
key assumptions. Second, fixed costs to contracting seem to be important as fixed costs, combined with convex variable costs to contracting, implies that outsourcing will occur for cities choosing moderate service levels, with both low levels and high levels being produced in-house. From a transaction cost standpoint, the empirical results highlight the importance of fixed contracting costs in the local public service literature. From a political economy standpoint, the results suggest that interest group politics are important in considerations with city service outsourcing.

The remainder of this paper is as follows. The next section presents the model, including its comparative static properties. Section three then presents the empirical methodology, data and results of the analyses of the 1990 and 2000 data. Section four concludes with a discussion and summary of the findings, as well as suggested directions for future research.

\section{Model}

This section explores the types of policies that emerge under competition between two office-seeking candidates when candidates have multiple modes of public service provision at their disposal and voters are heterogenous in their preferences and size of their tax base. The first subsection posits the preferences of voters and the technology by which politicians can turn tax dollars into the public service. The second subsection explores the probabilistic nature of elections and the platforms and policies that result from citizen characteristics and other given parameters. The third subsection explores comparative static properties, especially related to how demographic shifts affect the probability of outsourcing.

\subsection{Preferences and Public Good Production Technology}

Consider a city inhabited by a continuum of citizens with a population mass equal to one. These citizens are indexed by $i$ and each citizen $i$ is a member of only one group $j$. There are two groups in society, $j \in\{Y, O\}$ (for young and old) and each group makes up $\alpha^{j}$ fraction of the population, so that $\alpha^{Y}+\alpha^{O}=1$. Group members share two things in common. One is their tastes for the public service. ${ }^{7}$ Specifically, each group member has the same basic quasi-linear preferences over private consumption $c$, and the publicly provided service $g$, which is given by

$$
W^{j}=c^{j}+\lambda^{j} \ln (g)
$$

where $\lambda^{j} \geq 0$ represents intensity of preference for the public good; this taste parameter is common to all citizens in group $j$. Individuals in the same group also

\footnotetext{
${ }^{7}$ Of course cities provide an array of goods and services and there are important externalities across services. The single service assumption here is for simplicity; an extension of this model can incorporate multiple public services.
} 
have in common the size of their tax base, represented by $y^{j}$. For now, interpret $y^{j}$ as income. ${ }^{8}$ The public service is financed by a uniform proportional tax $\tau$ on income that is common to all citizens. After tax income is consumed; thus consumption for a member of group $j$ is given by $c^{j}=(1-\tau) y^{j}$. Substituting for consumption, equation (1) becomes

$$
U^{j}\left(g, \tau, \lambda^{j}, y^{j}\right)=(1-\tau) y^{j}+\lambda^{j} \ln (g)
$$

The production function for the public service is a simple linear transformation of labor units into units of output, but public service provision must be undertaken in one of two possible ways, or modes. Denote mode of provision by $x$. In the first mode, the city can provide the public service through the make technology, (inhouse provision) so that $x=\mu$. In this case the city hires and manages employees. Alternatively, the city can buy the service (privatized provision) so that $x=\beta$. In this case the city contracts with another entity that produces the service. Let the city's balanced budget equation under in-house provision be given by

$$
\tau^{\mu} y=w^{\mu} g^{\mu}+s
$$

where the superscript $\mu$ refers to in-house provision mode, or "make". The proportional tax rate and public service level are now written with a superscript indicating the mode of provision, as the correspondence between service level and tax rate, given by the balanced budget equation (3), is now mode dependent. $y$ is the average tax base, equal to the average tax base (income) in the city ( $\left.y=\Sigma_{j} \alpha^{j} y^{j}\right)$, and $w^{\mu}$ is the wage that must be paid to a public manager to produce one unit of output. Finally, $s$ represents the setup costs (fixed costs) the city must incur to engage in production.

The other option for the city is to "buy" the service. Let the balanced budget equation when the service is contracted-out be given by

$$
\tau^{\beta} y=w^{\beta} g^{\beta}+d\left(g^{\beta}, r\right)
$$

The superscript $\beta$ refers to "buy." $w_{\beta}$ is the wage that must be paid to a private manager to produce one unit of output. By assumption, $w_{\beta}<w_{\mu}$, that is a private company's cost of production is always less than a government's. ${ }^{9}$ The second

\footnotetext{
${ }^{8}$ City governments obtain their revenue from taxes on a variety of sources, including personal and corporate income taxes, sales and excise taxes. The predominant source of tax revenue are property taxes. In 1996, property taxes accounted for 74 percent of local government tax revenues, and sales taxes, personal income taxes and excise taxes accounted for about 15, five and five percent of revenue, respectively (Garrett and Leatherman, 2000). Therefore for some purposes, housing value is the most important tax base. However, interpreting the tax base as income best reflectes the simple notion that having more of the public good means less of everything else, and that the size of one's taxes will depend on the size of one's tax base.

${ }^{9}$ The wages are taken as parameters given to the model, however these relative wages have microfoundations. See the appendix for the outline of a moral hazard problem that derives this result formally, due to Levin and Tadelis (2007). However, the assumption that $w_{\beta}<w_{\mu}$ can also be motivated informally by appealing to the profit motive. In this case, the high powered incentive prinarily affects the owner of the firm rather than lower level employees.
} 
term on the right hand side of equation $(4), d(g, r)$, represents the contracting cost curve. Conceptually, contracting costs include the costs of all aspects of contracting. Therefore, while the model assumes that $w_{\beta}<w_{\mu}$, it can be true that $\tau^{\beta}>\tau^{\mu}$ for some given service level $g$ if $d(\cdot)$ is substantially higher than $s$. Contracting costs rise with the service level, $g$. For example, a higher $g$ could be more costly to contract over simply because writing more detailed contracts requires more paper. ${ }^{10}$ The other argument in the contracting cost curve is $r$, a general catch-all for how difficult it is to contract in the city. It includes potentially a wide variety of characteristics of the environment. ${ }^{11}$

Throughout, this paper assumes that $\frac{\partial d}{\partial g}>0$, because specifying and monitoring a higher level is more costly and that $\frac{\partial d}{\partial r}>0$, because $r$ by definition describes the difficulty of contracting. However two other assumptions are less strict: $d(0, r) \in \mathbb{R}$ and $\frac{\partial d^{2}}{\partial g \partial g} \in \mathbb{R}$. The first of these assumptions captures the notion that there could be fixed costs to contracting, ${ }^{12}$ and the second assumption reflects the fact that there could be either economies of scale or diseconomies of scale to contracting. ${ }^{13}$

Solving equations (3) and (4) for $\tau^{\mu}$ and $\tau^{\beta}$ respectively, and substituting them back into equation (2), each in turn, yields the two utility functions given below.

$$
\begin{gathered}
U^{j}\left(g^{\mu}, \lambda^{j}, y^{j}, y, s, w^{\mu}\right)=\left(1-\frac{w^{\mu} g^{\mu}+s}{y}\right) y^{j}+\lambda^{j} \ln \left(g^{\mu}\right) \\
U^{j}\left(g^{\beta}, \lambda^{j}, y^{j}, y, r, w^{\beta}\right)=\left(1-\frac{w^{\beta} g^{\beta}+d\left(g^{\beta}, r\right)}{y}\right) y^{j}+\lambda^{j} \ln \left(g^{\beta}\right)
\end{gathered}
$$

\footnotetext{
${ }^{10}$ There are many reasons even drawing up contracts could be more costly for higher service levels, where service level includes both quality and quantity aspects. For example in the context of ambulances, it may be easier to monitor ambulance response times than to develop clever ways to ensure paramedics are always delivering the correct lifesaving techniques inside the ambulance. Both higher response times and better techniques represent higher quality, and to achieve either may require more quantity.

${ }^{11}$ A monopolistically competitive firm's higher price enters the cost of production through $r$. It may be more conventional to think of a city with few suppliers as affecting the wage $w$. However, one can also interpret this as a haggling cost and thus a transaction cost incurred by the city.

${ }^{12}$ Fixed costs to contracting could include learning about the contracting process, search costs incurred while locating a lawyer, and potentially costs that are more political in nature, such as dealing with striking employees. The appendix presents the outline of an extension to the model where externalities exist across services, and outsourcing one service will affect the cost of providing other services, thus representing a fixed cost.

${ }^{13}$ Bajari and Tadelis (2001) develop a model with constant returns to scale to contracting. Contracting over quality is interpreted as contracting over contingencies. If each contingency is equally costly to cover, then people first contract over the contingencies that are most likely to occur, and so contracting costs will be convex in quality. However, changing one of the assumptions of Bajari and Tadelis (2001), if there are sufficient economies of scale to contracting over contingencies, a concave contracting cost curve $d(g, r)$ can result, even when some contingencies have a low probability of occurring. Thus, it is not clear a priori whether there are constant returns to scale (or decreasing returns to scale) to contracting, which implies $d(g, r)$ is convex, or if there are increasing returns to scale, implying $d(g, r)$.is concave.
} 


\subsection{Political Competition and Platform Determination}

While equations (5) and (6) represent the voters' basic preferences under each public service provision mode, voters are assumed not to vote deterministically, at least from the perspective of the candidates (and the econometrician). Another dimension, unrelated to policy, also affects voter utility and is represented here by two uniformly distributed random variables. ${ }^{14}$ The first random variable is $\sigma^{i j}$ and this is specific to each individual, but is drawn from a distribution that is common to that individual's group $j$ so that in addition to $y^{j}$ and $\lambda^{j}$, groups also share the same distribution of their $\sigma^{i j}$. The second random variable $\delta$ which is common to each citizen in the population. There are two political candidates, $k=A, B$ and the random variables represent a citizen's non-policy based bias towards (or if negative, against) candidate $B$. The timing is as follows: candidates become aware of citizen characteristics $\left(y^{j}, \lambda^{j}\right)$, given parameters $\left(w^{x}, r, d(0, r), s\right)$ and the distributions of $\sigma^{i j}$ and $\delta$. Next, candidates announce platforms, $\left(g_{A}^{x}, g_{B}^{x}\right)$. Then uncertainty is resolved $\left(\sigma^{i j}\right.$ and $\delta$ are determined), elections are held, and the winning candidate implements his platform. In the election stage, citizen $i$ in group $j$ votes for candidate $A$ only if

$$
U^{j}\left(g_{A}\right) \geq U^{j}\left(g_{B}\right)+\sigma^{i j}+\delta
$$

$\sigma^{i j}$ is distributed uniformly over the support $\left[\frac{-1}{2 \phi^{j}}, \frac{1}{2 \phi^{j}}\right]$ where $\phi^{j}$ is specific to group $j$, and $\delta$ is distributed uniformly over the support $\left[\frac{-1}{2 \psi}, \frac{1}{2 \psi}\right] . \phi^{j}$ will be interpreted as a group $j$ voter's "voting power". $\phi^{j}>0$ is assumed, and a high $\phi^{j}$ means $\sigma^{i j}$ is distributed over a short interval; in this case, voters base their vote less heavily on things unrelated to policy.

Given the platforms of both candidates, the vote share for candidate $A$ is given by

$$
\pi_{A}=\sum_{j} \alpha^{j} \phi^{j}\left(\sigma^{j}+\frac{1}{2 \phi^{j}}\right)
$$

where $\sigma^{j}$ is defined as $\sigma^{j}=U^{j}\left(g_{A}\right)-U^{j}\left(g_{B}\right)-\delta$. Defining $\sigma^{j}$ in this way simplifies solving the model mathematically but it also has an interpretation. A voter with $\sigma^{i j}=\sigma^{j}$ can be thought of as the "swing voter" in group $j$ - the voter who is indifferent from voting for candidate $A$ or $B$. Everyone in group $j$ with a value of $\sigma^{i j}$ less than $\sigma^{j}$ votes for candidate $A$. To see that equation (8) is candidate $A$ 's vote share, note that because $\sigma^{i j}$ is distributed over $\left[\frac{-1}{2 \phi^{j}}, \frac{1}{2 \phi^{j}}\right]$, the term $\phi^{j}\left(\sigma^{j}+\frac{1}{2 \phi^{j}}\right)$ is always between zero and one, and this represents the percent of group $j$ voters that

\footnotetext{
${ }^{14}$ This section of the model borrows from Persson and Tabellini (2000). As they discuss, the assumption of a uniform distribution is not crucial for the results to go through.
} 
vote for candidate $A{ }^{15}$ Candidate $A$ 's expected vote share is

$$
E \pi_{A}=\frac{1}{2}+\sum_{j} \alpha_{j} \phi_{j}\left[U^{j}\left(g_{A}\right)-U^{j}\left(g_{B}\right)\right]
$$

As candidates are assumed to be office-seeking, they announce platforms to maximize their expected vote share. Candidates are also assumed to have equal access to utilize either mode. To illustrate how candidates determine platforms in equilibrium, consider the problem facing Candidate $A$. If he uses the "make" production technology, the platform $\left(g_{A}^{\mu}\right)$ that maximizes his probability of winning solves

$$
\frac{\partial E \pi_{A}}{\partial g^{\mu}}=\sum_{j=O}^{Y} \alpha_{j} \phi_{j} \frac{\partial U^{j}\left(g_{A}^{\mu}\right)}{\partial g_{A}^{\mu}}=0
$$

Given the functional form assumption on $U(\cdot)$, equation (10) yields a unique solution for $g_{A}^{\mu}$, denoted $g_{A}^{* \mu}$. If instead candidate $A$ uses the "buy" production technology, an equation analogous to (10) shows how the optimal $g_{A}^{* \beta}$ is determined. (Equation (10) uses the utility curve from equation (5), so the analogous equation would simply use the utility function from equation (6) instead.) Candidate $B$ also performs analogous maximization problems for each mode; it will be the case that $g_{B}^{* \mu}=g_{A}^{* \mu}$ and $g_{B}^{* \beta}=g_{A}^{* \beta}$ because $E \pi_{B}$ is simply $1-E \pi_{A}$.

Each candidate $k \in\{A, B\}$ must decide which platform, $g_{k}^{* \mu}$ or $g_{k}^{* \beta}$ to announce, taking into account the action of the other candidate. In equilibrium, each candidate selects the platform that gives the highest probability of winning given the platform selected by the other candidate.

Proposition 1: There is a unique Nash equilibrium to the two-party probabilistic voting game with multiple production functions where each candidate announces the same platform. Moreover, the equilibrium platform $g^{*}$ that is chosen by both candidates is given by $g^{* \mu}$ whenever $\sum_{j} \alpha_{j} \phi_{j} U^{j}\left(g^{* \mu}\right) \geq \sum_{j} \alpha_{j} \phi_{j} U^{j}\left(g^{* \beta}\right)$ and is given by $g^{* \beta}$ whenever $\sum_{j} \alpha_{j} \phi_{j} U^{j}\left(g^{* \mu}\right)<\sum_{j} \alpha_{j} \phi_{j} U^{j}\left(g^{* \beta}\right)$.

Proof: Given candidates are optimizing, one can focus attention onto only four states of the world in the election stage: $\left(g_{A}^{* \mu}, g_{B}^{* \mu}\right),\left(g_{A}^{* \mu}, g_{B}^{* \beta}\right),\left(g_{A}^{* \beta}, g_{B}^{* \mu}\right)$ or $\left(g_{A}^{* \beta}, g_{B}^{* \beta}\right)$. However if each candidate is offering a different platform, it implies one candidate has a probability of winning that is greater than .5 and the other a probability of winning that is less than .5; thus one candidate could change platforms and strictly increase his chance of winning, ${ }^{16}$ which eliminates both $\left(g_{A}^{* \mu}, g_{B}^{* \beta}\right)$ and $\left(g_{A}^{* \beta}, g_{B}^{* \mu}\right)$ as possible equilibria. Finally, only one of either $\left(g_{A}^{* \mu}, g_{B}^{* \mu}\right)$ or $\left(g_{A}^{* \beta}, g_{B}^{* \beta}\right)$ will be an

\footnotetext{
${ }^{15}$ The distribution on $\delta$ is assumed to not be too wide in order to rule out a corner solution. For simplicity, $\psi=\min \left\{\phi^{Y}, \phi^{O}\right\}$.

${ }^{16}$ This is true unless the optimized in-house and privatized platforms coincide. However continuity ensures that this is a measure zero event.
} 
equilibrium, as one is inferior in the sense that, in the inferior case, either candidate could unilaterally change his platform to the optimal level with the other mode, which would yield a higher value to his expected vote share, equation (9), and thus strictly increase his chances of winning. Q.E.D.

This proof generalizes results from the probabilistic voting literature to account for multiple production functions; here, the production functions are taken from the transaction cost economics literature. While the proof rests on the concept of Nash equilibrium, it is straightforward to extend it to the concept of subgame perfection if platform announcements are sequential. In this setup, the random variable $\delta$ essentially decides the election. However more importantly, the parameters of the model - $\alpha^{j}, \lambda^{j}, \phi^{j}, y^{j}, w^{x}$, and $r$ - decide policy.

\subsection{Comparative Statics}

This subsection explores how changes in the variables of the model effect likelihood of outsourcing. Of particular interest is how changes in the size of the elderly voter group affects the likelihood of outsourcing. To answer this question, one must first understand how changes in the size of the elderly voter group affects service level. Through equation (10) and equation (5), one can see that $g^{* \mu}$ solves the following for $g$ (derivation in appendix):

$$
g w_{\mu}=\frac{y\left(\alpha^{O} \phi^{O} \lambda^{O}+\alpha^{Y} \phi^{Y} \lambda^{Y}\right)}{\left(\alpha^{O} \phi^{O} y^{O}+\alpha^{Y} \phi^{Y} y^{Y}\right)}
$$

where $y=\alpha^{Y} y^{Y}+\alpha^{O} y^{O}$. Note that dividing both sides by $w_{\mu}$ yields a closed form solution for $g^{* \mu}$, and it is then straightforward to take a partial derivative. The solution using the buy production technology, found by inserting (6) into (10), however, does not have a closed form. Nonetheless, one can characterize $g^{* \beta}$ as solving the following for $g$ :

$$
g w_{\beta}+g d_{g}(g, r)=\frac{y\left(\alpha^{O} \phi^{O} \lambda^{O}+\alpha^{Y} \phi^{Y} \lambda^{Y}\right)}{\left(\alpha^{O} \phi^{O} y^{O}+\alpha^{Y} \phi^{Y} y^{Y}\right)}
$$

This is an equation whose right-hand side is identical to the right-hand side of the previous equation. Denote the expression on the right-hand sides of (11) and (12) by $\Omega$. Although one cannot derive a closed form solution for $\frac{\partial g^{* \beta}}{\partial \alpha^{O}}$ without imposing functional form assumption on $d(g, r)$, one can still characterize the direction of the comparative static, if not its precise magnitude. If $\frac{\partial \Omega}{\partial \alpha^{O}}>0$ then both $\frac{\partial g_{\mu}^{*}}{\partial \alpha^{O}}>0$ and $\frac{\partial g_{\beta}^{*}}{\partial \alpha^{O}}>0$ because the left hand sides of both (11) and (12) are monotonically increasing in $g$, so that if the right-hand side $(\Omega)$ increases, $g$ must increase in the left-hand side of both equations to preserve the equality. Therefore, by studying $\Omega$, one can gain a sense of the directional effect of a demographic shift on equilibrium service level $g^{*}$. 
Demographic shifts affect service level through three channels: an tax base effect, a preference-power effect, and a tax-payer-power effect. First, the tax base effect causes $y$ in the numerator of $\Omega$ to change; an increase in average tax base will contribute to a service level increase. If the portion of elderly increases, then average tax base will increase if $y^{O}>y^{Y}$ and will decrease if the reverse holds. ${ }^{17}$ Second, the preferencepower effect comes through the second term in the numerator of $\Omega,\left(\alpha^{O} \phi^{O} \lambda^{O}+\right.$ $\left.\alpha^{Y} \phi^{Y} \lambda^{Y}\right)$. If the portion of elderly increases, the preference-power effect will be positive, and will contribute towards an increase in service level if $\phi^{O} \lambda^{O}>\phi^{Y} \lambda^{Y}$, that is, if the elderly's preference for the publicly provided good, weighted by their voting power, is stronger than the preference of the young, weighted by their own voting power. ${ }^{18}$ Finally, the tax-payer-power effect influences service level though the term $\left(\alpha^{O} \phi^{O} y^{O}+\alpha^{Y} \phi^{Y} y^{Y}\right)$, the denominator of $\Omega$. If the portion of elderly voters increases, the tax-payer-power effect serves to decrease service level if $\phi^{O} y^{O}>\phi^{Y} y^{Y}$ (and will increase service level if the reverse holds.) This reducing effect comes about as, although voters may enjoy consuming the publicly provided good, they are averse to paying for it. In sum, one must take into account the combined influence of all three forces when analyzing how a demographic change affects changes in service level. If $\lambda^{O}>\lambda^{Y}, \phi^{O}>\phi^{Y}$ and $y^{O}>y^{Y}$, as seems plausible given the balance of the extant data and literature, it can be shown that the positive preference-power and tax base effects outweigh the negative tax-payer-power effect, so that service level increases when the portion of elderly voters increases. However, even if one of these conditions does not hold, for example if $y^{O}<y^{Y}$, the derivative can still in fact be positive, as long the tax base of the old is not "too much" less than that of the young. The cutoff point, when yo is much less than yy, occurs when the negative tax base effect from the increasing size of a poor, elderly populaiton, overtakes the postive payer-power effect. All of the above claims are shown in more detail in the appendix.

The table below summarizes how some of the variables of the model affect service level, and the conditions under which the stated comparative static direction holds.

\footnotetext{
${ }^{17}$ That the income of the elderly is larger than that of the young (i.e. $y^{O}>y^{Y}$ ) seems to be an unreasonable assumption for most cities. However, it is quite plausible if housing value is the tax base. In Census data for the 200 largest U.S. cities in 2000, the ratio of average housing value for householders older than 65 to average housing value for householders between the ages of 15-64 was 1.3. Only 25 cities had a ratio less than one, and only four cities had a ratio less than .8 .

${ }^{18}$ As discussed in the introduction, $\lambda^{O}>\lambda^{Y}$ is likely to hold. As for the relationship between $\phi^{O}$ and $\phi^{Y}$, Campbell (2003) explains that the elderly are more likely to have their policy preferences realized than other groups, partly as a result of their high rate of voting participation. Indeed, a recent survey conducted by the Pew Research Center (2006) shows that a person of age over 65 is nearly twice as likely as the average 18-29 year old to be a regular voter, and is nearly three times as likely to be registered to vote. If this research implies that $\phi^{O}>\phi^{Y}$, for example, if voter turnout is correlated with voting power, then this condition is more likely to hold. The interpretation of $\phi^{j}$ as a measure of abstention makes sense in the reduced form version of the model, as candidate A maximizes his expected vote share, $E \pi_{A}=\frac{1}{2}+\sum \alpha_{j} \phi_{j}\left[U^{j}\left(g_{A}\right)-U^{j}\left(g_{B}\right)\right]$. In this case, $\phi$ can be thought of as a measure of the fraction of eligible voters, $\alpha$, that actually vote.
} 
As mentioned in the above paragraph, the condition for $\frac{\partial g^{*}}{\partial \alpha^{O}}>0$ is overly restrictive; it is sufficient but not necessary for this comparative static direction to hold.

\begin{tabular}{|l|l|}
\hline Table 1 Effect of Variable Change on Equilibrium Service Level \\
\hline $\begin{array}{l}\text { Direction of } \\
\text { Comparative Static }\end{array}$ & Condition \\
\hline$\frac{\partial g^{*}}{\partial \alpha^{O}}>0$ & $\lambda^{O}>\lambda^{Y}, \phi^{O}>\phi^{Y}$ and $y^{O}>y^{Y}$ \\
$\frac{\partial g^{*}}{\partial \lambda^{O}}>0$ & $\alpha^{O} \neq 0$ \\
$\frac{\partial g^{*}}{\partial \lambda^{Y}}>0$ & $\alpha^{Y} \neq 0$ \\
$\frac{\partial g^{*}}{\partial y^{O}}<0$ & $\phi^{O}>\phi^{Y}$ \\
$\frac{\partial g^{*}}{\partial y^{Y}}>0$ & $\phi^{O}>\phi^{Y}$ \\
$\frac{\partial g^{*}}{\partial \phi^{O}}>0$ & $\frac{\lambda^{O}}{y^{O}}>\frac{\lambda^{Y}}{y^{Y}}$ \\
$\frac{\partial g^{*}}{\partial \phi^{Y}}<0$ & $\frac{\lambda^{O}}{y^{O}}>\frac{\lambda^{Y}}{y^{Y}}$ \\
\hline
\end{tabular}

As service level $g$ varies with some parameters of the model, the change in service level affects the likelihood of outsourcing. First, consider how an exogenous change in service level $g$ affects likelihood of outsourcing. Then, working backwards, it is possible to say how the variables of the model affect likelihood of outsourcing as table 1 shows how the variables of the model affect service level $g$. Consider figure 1a, which plots four separate cases of both balanced budget constraints (equations 3 and 4) on the same graph. The shape of the "buy" balanced budget constraint depends on two parameters of the contracting cost curve; as described in section 2.1, two assumptions on contracting costs are flexible: $d(0, r) \in \mathbb{R}$ and $\frac{\partial d^{2}}{\partial g \partial g} \in \mathbb{R}$. Exploring the model at different points in these two dimensions of parameter space yields four scenarios, one for each pair of contracting cost curve assumptions, with the tax-base $\tau y$ on the $\mathrm{y}$-axis and service level $g$ on the $\mathrm{x}$-axis.

As long as fixed costs to contracting are not too high in the convex case, and setup costs are not too high in the concave case, there could be only one or two points of intersection of these two curves. ${ }^{19}$ The lower envelope is associated with the least cost mode for any given level $g$ and these points of intersection can be thought of

\footnotetext{
${ }^{19}$ This holds as long as $\frac{\partial d^{2}}{\partial g \partial g} \neq 0$.
} 
as "kink" points on the lower envelope. If something causes the level of service to move nearer to a kink point, it can be interpreted as increasing probability of regime change, and if the kink point marks a regime change from $g^{* \mu}$ to $g^{* \beta}$, one can say the likelihood of outsourcing increases. On the other hand, if the kink point marks a regime change from $g^{* \beta}$ to $g^{* \mu}$, one can say the likelihood of outsourcing decreases as the level becomes nearer to the kink point. The number of kink points, and whether they mark a regime change from $g^{* \mu}$ to $g^{* \beta}$ or vice versa, is a function of the two dimensions of contracting costs. The prediction for how an increase in service affects likelihood of outsourcing (denoted by $\mathcal{L}$ ) for each set of contracting curve is illustrated in figure $1 \mathrm{~b}$.

Proposition 2: Depending on the values of $d(0, r)$ and $\frac{\partial^{2} d}{\partial g \partial g}$, the likelihood of outsourcing is either increasing, decreasing, U-shaped, or inverted U-shaped with respect to service level, is one (always buy) or zero (always make.) With high fixed costs and concave contracting cost curve (CCC), the likelihood of outsourcing is increasing as service level increases; with low fixed costs and a convex CCC, likelihood of outsourcing is decreasing as service level increases; with low fixed costs and concave CCC, likelihood of outsourcing is U-shaped as service level increases; and with high fixed costs and a convex CCC, likelihood of outsourcing is inverted U-shaped as service level increases. If setup costs are very high in the concave case, outsourcing will always occur, and if fixed contracting costs are very high in the convex case, outsourcing will never occur.

Proof: Interpreting service levels moving closer to kink points as higher likelihoods of regime change establishes the claims in proposition 2.

For example, consider the case of an increase in $g$, perhaps brought about by an increase in $\lambda^{O}$ (or $\alpha^{O}$ when the necessary conditions are met). This will cause the likelihood of outsourcing to decrease in the case of a convex contracting cost curve without fixed costs, increase in the case of a concave contracting cost curve (CCC) with fixed costs, decrease at first and then increase (U-shaped) in the concave CCC without fixed costs case, and decrease at first and then increase (inverted U-shaped) in the convex CCC with fixed costs case. Thus, the model outlined in the previous subsections generates four hypotheses for how changes in service level affect likelihood of outsourcing. Without a strong theoretical prior on the shape of the CCC, only empirical analysis can shed light on which hypothesis may be valid. This empirical problem is the topic of the next section, and the empirical results will be used to reject some of the hypotheses. 
Figure 1a Tax Price and Service Level

Convex Variable
Contracting Costs

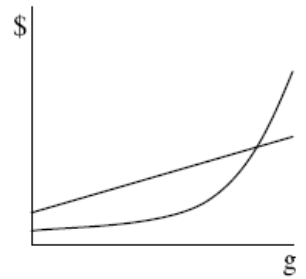

Low Fixed Contracting Costs

High Fixed Contracting Costs

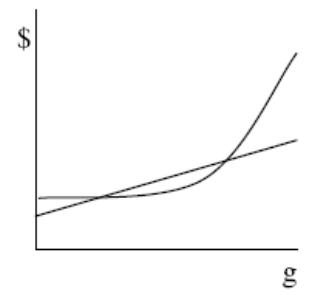

Concave Variable

Contracting Costs
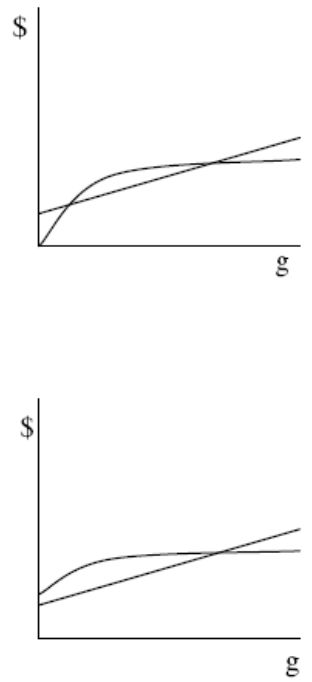

Figure 1b Likelihood of Outsourcing and Service Level

Low Fixed Contracting Costs

Convex Variable

Contracting Costs

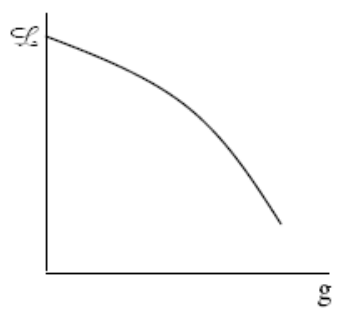

High Fixed Contracting Costs
Concave Variable

Contracting Costs
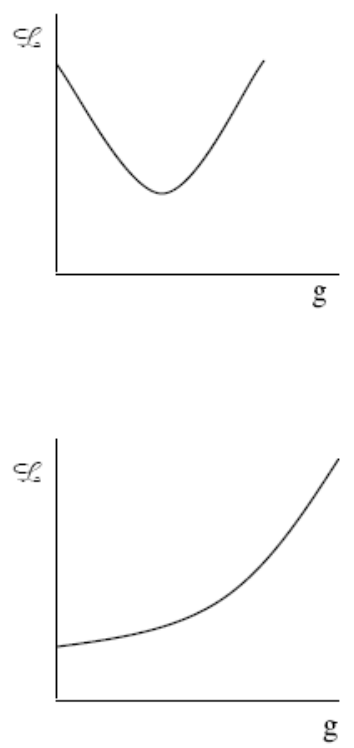
A few comparative statics remain to establish. Until now this subsection has only described the comparative static properties of the model for changes in the demographic and political economy variables $\alpha, \phi, y$ and $\lambda$ and has said nothing about the industrial organization variables $r, w, d(0, r)$ and $s$. The effect of a change in these variables on likelihood of outsourcing is much more straightforward, as their effects do not depend on service level and the shape of the contracting cost curve. Consider how these variables affect the lower envelope of the two balanced budget equations in figure 1 . If the fixed costs to contracting $d(0, r)$ increase, then the likelihood that a random service level will be produced with buy technology decreases; thus the likelihood of outsourcing decreases. The same hold true for the contracting difficulty $r$ and the wage for private contractor $w^{\beta}$. Conversely, if the setup costs to in-house provision increase, then the likelihood that any service level will produced with make technology decreases, and the likelihood of outsourcing increases, and the same holds true for the wage for in-house producer $w^{\mu}$.

\begin{tabular}{|c|c|c|c|}
\hline $\begin{array}{l}\text { An increase in } \\
\text { this variable... }\end{array}$ & \multicolumn{3}{|c|}{$\begin{array}{l}\text {..causes likelihood } \\
\text { of outsourcing to: }\end{array}$} \\
\hline \multirow{3}{*}{$g$} & $\frac{\partial d^{2}}{\partial g \partial g} \geq 0$ & $\frac{\partial d^{2}}{\partial g \partial g}<0$ & \multirow{3}{*}{$\begin{array}{r}\leftarrow \text { assumptions } \\
\downarrow \\
d(0, r)<s \\
d(0, r) \geq s\end{array}$} \\
\hline & decrease & $\begin{array}{l}\text { decrease, } \\
\text { then increase }\end{array}$ & \\
\hline & $\begin{array}{l}\text { increase, } \\
\text { then decrease }\end{array}$ & increase & \\
\hline$r$ & \multicolumn{3}{|l|}{ decrease } \\
\hline$w^{\mu}$ & \multicolumn{3}{|l|}{ increase } \\
\hline$w^{\beta}$ & \multicolumn{3}{|l|}{ decrease } \\
\hline$d(0, r)$ & \multicolumn{3}{|l|}{ decrease } \\
\hline$s$ & \multicolumn{3}{|l|}{ increase } \\
\hline
\end{tabular}

When interpreting the model it is crucial to distinguish between those variables that affect likelihood of outsourcing directly (e.g. those listed in the bottom half of table 2), versus those that affect likelihood of outsourcing though service level (e.g. $g$, and those in table 1). The effect of an increase in service level on likelihood of outsourcing depends on the two assumptions on the contracting cost curve, and will 
therefore be determined empirically. The most important comparative static for this purpose is on $\alpha^{O}$. If the percent of the voting age population over 65 increases then service level will increase, but it is unclear if this increase in service level will cause likelihood of outsourcing to increase, decrease, or be U-shaped or inverted U-shaped.

\section{$3 \quad$ Data and Empirical Methodology}

The goal of the empirical section is straightforward - to see how the percent of elderly voters in a city is correlated with ambulance outsourcing. The empirical model used here is a Probit, and mode of emergency ambulance transport provision is the dependent variable, with buy equal to one and make equal to zero. ${ }^{20}$ The theoretical model of the previous section generates four competing hypotheses for how the percent elderly correlates with outsourcing, depending on the shape of the contracting cost curve. The empirical results presented in this section will be used to distinguish between them, and thus to identify the shape of the contracting cost curve. In particular, this section will investigate whether the relationship between percent elderly and outsourcing is either monotonically increasing or decreasing, Ushaped, inverted U-shaped, or other. Any correlation consistent with one of the first four relationships is consistent with one specific version of the model, while any other correlation (or lack of a correlation) is not consistent with the model. The correlation between a number of the other variables is also of interest, and several of them can be used to judge the validity of the model. .

As a digression, perhaps a more direct test than the one proposed above would be to see how variation in quality level correlates with outsourcing. Unfortunately, direct empirical measures for quality level of the service are difficult to obtain for a number of reasons. First, public service quality is inherently hard to measure (Tirole, 1994). Also, even when it would have been possible to gather a decent measure of quality, no entity to date could be found that has made available such data. ${ }^{21}$ This lack of data on quality explains the approach taken here; it is not possible to see how quality correlates with outsourcing, but it is possible to say what affects quality, though the model developed in the previous section.

Alternatively one may prefer to see if expenditure data correlates with outsourcing. Here too, good data for ambulance expenditures are difficult to obtain, because they are often combined with data on first responders under the heading emergency medical service (EMS $)^{22}$ and because this type of data is often lumped together with

\footnotetext{
${ }^{20}$ The data appendix contains the details of how the data was recoded into either make or buy.

${ }^{21}$ The lack of data on EMS performance, and its effect, was lamented in a series of articles published by Robert Davis in USA Today beginning on 7/28/2006.

${ }^{22}$ There are many components to what is commonly known as EMS. Many surveys ask about emergency medical service as if it were one service. In fact, there are two main components: first responder service, and transport service. A first responder is the first unit dispatched to the emergency scene, usually by a central 911 center. In the majority of cases, the city owned
} 
expenditures for fire departments. Also, there is no guarantee that high expenditures necessarily leads to high quality.

Data for the dependent variable come from the Journal of Emergency Medical Service (JEMS) for the years 1990 and 2000 (published in 1991 and 2001, respectively) and these provide the basis for two separate data sets. JEMS is a trade publication that produces an annual survey of emergency medical services, both first-responder and transport providers, in the 200 largest U.S. cities. This data is highly detailed, including the type, name and address of all emergency ambulance providers in a community. ${ }^{23}$ The independent variables come from a number of different sources. The following tables summarize all the variables used in this study, their relationship to the theoretical model, and summary statistics.

Several of the independent variables used here are from the 1990 and 2000 Decennial Census (summary file 3). The fraction of the voting age population over 65 (a proxy for $\alpha^{O}$ ) is the variable that is of primary interest in this study, as ambulances are a service for which the elderly are a particularly important group. ${ }^{24}$ The value of the square of this term is also critical, to distinguish between the four main hypotheses of the theoretical model; thus there are no expected signs for population $>$ 65 nor its square. Also from the Census, the value of owner-occupied housing units without a mortgage over number of households over 65 (approximate value of houses owned by elderly) divided by value of owner-occupied housing units with a mortgage over number of households between 18 and 65 (approximate value of houses owned by young) creates the variable $\left(y^{O} / y^{Y}\right)$. If the elderly have a larger tax base than the young, then the elderly will be paying for a larger portion of the public service, and this will serve to reduce the service level. Therefore while cities with a large portion of the population over 65 should have a high service level, the theoretical model suggests the relative tax base variable is also important.

fire department has responsibility for first responding, and it is not uncommon for a fire truck to be dispatched for this purpose. After stabilizing the situation, a transport vehicle (ambulance) typically arrives to take the patient to a hospital if further care is required. It may be the case that the ambulance is both the first responder and transport provider, but it is never the case that the fire truck is both, as fire trucks lack the capability of carrying patients in a horizontal position. Other data sets that have been used in previous literature, for example, those collected by the International City Managers Association (ICMA) and U.S. Census Bureau's Census of Government (Organizational Phase) do not differentiate between these two distinct components of EMS.

${ }^{23}$ Private ambulances exist in almost all communities, however these ambulances do not always provide emergency transport service, the focus of this study. Many of these provide hospital-tohospital, home-to-hospital, or other types of transport, but not emergency transport of the sort that is paid for by the local government.

${ }^{24}$ Although the theoretical model suggests the fraction of the voting age population that is elderly is the appropriate measure to use here, it is possible that the absolute number of elderly voters affects the outsourcing decision in a different way, for example, by representing a "critical mass" to form an interest group. Although the results when the absolute number of elderly are used are not reported here, they do not differ substantially than when the fraction of elderly is used. However when both the fraction and number are included simutanously, insignificant results obtain, likely do to colinearity between the two measures. 


\begin{tabular}{|c|c|c|}
\hline Variable & Description & $\begin{array}{l}\text { Model } \\
\text { Proxy }\end{array}$ \\
\hline mode & Mode of ambulance provision; "make" $=0$, "buy" $=1$ & $x$ \\
\hline $\log (\mathrm{pop})$ & Logarithm of the city's population & $s, d(0, r)$ \\
\hline $\log ($ house_value $)$ & Logarithm of the average housing value in the city & $y, r$ \\
\hline $\begin{array}{l}\text { population }>65 \\
\text { population }>65 \mathrm{sq}\end{array}$ & $\begin{array}{l}\text { Fraction of voting age population above } 65 \text { years of age } \\
\text { the square of population }>65\end{array}$ & $\begin{array}{l}\alpha^{O} \\
\alpha^{O}\end{array}$ \\
\hline hvalue65/hvalue18 & $\begin{array}{l}\text { total housing value of residents over } 65 \text { years of age, over } \\
\text { the total housing value of residents between } 18 \text { and } 65 \\
\text { years of age }\end{array}$ & $y^{O} / y^{Y}$ \\
\hline $\begin{array}{l}\text { union } \\
\text { fire_union }\end{array}$ & $\begin{array}{l}\text { fraction of all city government employees in unions } \\
\text { fraction of city fire department employees in unions }\end{array}$ & $\begin{array}{l}d(0, r) \\
d(0, r)\end{array}$ \\
\hline relative_wage & $\begin{array}{l}\text { Average wage of city employees over average wage of } \\
\text { private sector employees in the county in which the city is } \\
\text { located }\end{array}$ & $w^{\mu} / w^{\beta}$ \\
\hline fire_wage & $\begin{array}{l}\text { Average wage of fire employees over wage of private sector } \\
\text { employees in county in which city is located }\end{array}$ & $w^{\mu} / w^{\beta}$ \\
\hline no strike & $\begin{array}{l}\text { Dummy indicating state law prohibits city employees from } \\
\text { striking }\end{array}$ & $r$ \\
\hline unemployment & Unemployment rate in county in which city is located & $r$ \\
\hline ideology & $\begin{array}{l}\text { Percent of votes for Bush in county in which city is } \\
\text { located }\end{array}$ & $r$ \\
\hline no pol activity & $\begin{array}{l}\text { Dummy indicating state law prohibits political activity by } \\
\text { city employee }\end{array}$ & $r$ \\
\hline merit & $\begin{array}{l}\text { Dummy indicating state law requires cities use a merit } \\
\text { system in hiring }\end{array}$ & $r$ \\
\hline standards & Dummy indicating state law sets city purchasing standards & $r$ \\
\hline debt limit & Dummy indicating debt limits imposed on cities, & $r$ \\
\hline borrowing & $\begin{array}{l}\text { Dummy indicating state law permits short-term borrowing } \\
\text { by cities }\end{array}$ & $r$ \\
\hline take over & $\begin{array}{l}\text { Dummy indicating state law authorizes state "take over" of } \\
\text { city finances }\end{array}$ & $r$ \\
\hline balanced budget & $\begin{array}{l}\text { Dummy indicating state law mandates city have a balanced } \\
\text { budget }\end{array}$ & $r$ \\
\hline state assess & $\begin{array}{l}\text { Dummy indicating property tax assessment is a state } \\
\text { function }\end{array}$ & $r$ \\
\hline
\end{tabular}




\begin{tabular}{|c|c|c|c|c|c|c|c|c|c|c|}
\hline \multirow[b]{2}{*}{ Variable } & \multicolumn{5}{|l|}{1990} & \multicolumn{5}{|l|}{2000} \\
\hline & Mean & SD & Min & Max & Obs & Mean & SD & Min & Max & Obs \\
\hline mode & .65 & .47 & 0 & 1 & 200 & .57 & .50 & 0 & 1 & 200 \\
\hline $\log (\mathrm{pop})$ & 12.24 & .75 & 10.33 & 15.81 & 200 & 12.37 & .72 & 11.49 & 15.90 & 200 \\
\hline log(house_value) & 10.66 & .54 & 9.23 & 12.26 & 200 & 11.09 & .52 & 9.42 & 12.44 & 200 \\
\hline population $>65$ & .16 & .04 & .05 & .35 & 200 & .15 & .04 & .07 & .22 & 200 \\
\hline population $>65 \mathrm{sq}$ & .03 & .02 & .003 & .12 & 200 & .02 & .01 & .005 & .05 & 200 \\
\hline hvalue65/hvalue18 & 1.61 & .55 & .43 & 4.40 & 200 & 1.47 & .47 & .33 & 3.51 & 200 \\
\hline union & .43 & .34 & 0 & 1 & 199 & & & & & \\
\hline fire_union & .60 & .52 & 0 & 2.98 & 192 & & & & & \\
\hline relative_wage & 1.13 & .20 & .63 & 1.78 & 199 & 1.15 & .24 & .60 & 1.97 & 200 \\
\hline fire_wage & 1.36 & .33 & .14 & 2.48 & 192 & 1.41 & .39 & .46 & 3.06 & 183 \\
\hline unemployment & 5.38 & 1.85 & 2 & 12.9 & 200 & 3.97 & 1.22 & 1.6 & 10.4 & 200 \\
\hline ideology & .52 & .10 & .22 & .78 & 197 & .45 & .12 & .09 & .82 & 200 \\
\hline no pol activity & .50 & .50 & 0 & 1 & 199 & & & & & \\
\hline no strike & .04 & .18 & 0 & 1 & 199 & & & & & \\
\hline merit & .45 & .50 & 0 & 1 & 199 & & & & & \\
\hline standards & .78 & .41 & 0 & 1 & 199 & & & & & \\
\hline debt limit & .86 & .34 & 0 & 1 & 199 & & & & & \\
\hline borrowing & .10 & .30 & 0 & 1 & 199 & & & & & \\
\hline take over & .12 & .33 & 0 & 1 & 199 & & & & & \\
\hline balanced budget & .08 & .26 & 0 & 1 & 199 & & & & & \\
\hline state assess & .19 & .39 & 0 & 1 & 199 & & & & & \\
\hline
\end{tabular}

Two other variables from the the Decennial Census are population and average housing value, calculated as total housing value over number of households, and are both important control variables. While the model predicts level will not depend on $y$ (due to the quasi-linear nature of the utility function) it is still an important control variable, as it may have a tax base effect, or an influence on $r$ if contractors are attracted to richer areas, making it easier for cities to contract. Population may be related to both $s$ and $d(0, r)$. For example, large cities may experience economies of scale or scope in in-house production, and so may lower $s$. Larger cities may also have experience with contracting, lowering $d()$, but on the other hand, may face larger political fixed costs to contracting, for example, if there is a wage externality, as discussed in footnote 23, they have more employees affected. Therefore neither log of population nor log of average housing value has a prior expected sign.

Two variables relate to the unionization of city workers, and come from the U.S. Census Bureau's 1987 Census of Government (Employment Phase). The percent of all city workers in a union, and the percent of firefighters in unions may capture the value of $d(0, r)$. If there is high unionization of firefighters, for example, then 
it could be hard to privatize the service. If the city makes the service itself, it will usually do so through the fire department, and so fire departments may take actions to prevent losing responsibility for providing emergency ambulance service. Therefore the expected sign on both of the unionization variables is negative. Unionization data was not available in latter years, and is therefore only included in the 1990 regressions.

Another variable relates to the wage rates and is a measure for $w^{\mu} / w^{\beta}$. It comes from two sources: the public wage comes from the 1987 and 1997 Census of Government (Employment Phase), and the private wage from 1987 and 1997 County Business Patterns. The public wage is calculated as the total payroll divided by the number of workers, and the private wage is the average wage of private workers in the county in which the city is located, calculated in the same way. ${ }^{25}$ The model yields a clear prediction: $w^{\mu} / w^{\beta}$ should be negatively related to outsourcing according to the model.

Two additional variables, also used in previous studies, are unemployment in 1990 and 2000 (from the Bureau of Labor Statistics), and a measure of ideology. Unemployment affects labor market conditions, and Lopez et al. (1997) argue that politicians will have an incentive to keep services in-house to avoid political costs when unemployment is high. Thus, the expected relationship between unemployment and outsourcing is negative. As for ideology, more Republican leaning areas are expected to be associated with more outsourcing, as Republican's traditionally favor a smaller scope of government, compared to Democrats. Thus the expected relationship between ideology and outsourcing is positive. 1988 data on the percent of votes cast for the Republican presidential candidate (George H.W. Bush) in the county in which the city is located serves to proxy for ideology in the 1990 sample, and these data come from ICPSR. Similarly, the percent of votes for the Republican presidential candidate (George W. Bush) in the county in which the city is located serve to proxy for ideology in the 2000 presidential election for the 2000 data set; these are taken from http://cnn.com/elections. A standard theoretical interpretation for how ideology affects outsourcing involves recourse to a primitive preference for outsourcing. This notion is heuristic and does not make for very interesting theory, however plausible it may be.

Finally, the regressions also include a number of dummy variables. One is related to cost of employment. U.S. Advisory Commission on Inter-governmental Relations(USACIR) presents data on state laws that impact various aspects of city governance. Data from USACIR (1993), variable no strike, is a dummy variable that indicates a state-law prohibits city employees from striking. Lopez-de-Salinas etl al (1997) argue that...In terms of the model here, this interpretation would serve to reduce $w^{\mu}$. However no strike may also influence $d(0, r)$ thus its effect on likelihood

\footnotetext{
${ }^{25}$ Sometimes city borders cross county borders and a city will be located in more than one county. In this case, Google searches determined which county the city was primarily located in and the average private wage from this county was used.
} 
of privatization is ambiguous.

Other dummy variable serve to proxy for $r$, the catch-all variable in the model. USACIR variables include a number of "clean government variables" including: no pol activity (f15) indicating state law prohibits political activity by city or county employees, merit (f1) indicating state law requires cities to adopt a merit system, and standards (e14) indicating state law sets purchasing standards for local governments. All of these should be positively correlated with outsourcing, because "...the more difficult it is to pursue political ends through in-house provision of public services, the more likely local politicians are to privatize these services." (Lopez et al. 1997, p453). There are also a number of budget constraint variables: debt limit (e1) indicating debt limits are imposed by states on cities, borrowing (e7) indicating state law forbids short-term borrowing by local units, take over (e19) indicating state law authorizes state "take over" of the financial administration of the city, balanced budget (e24) indicating state constitution or statutory law mandates a balanced budget, and state assess (e23) indicating property tax assessment is a state function. All of these should be positively correlated with outsourcing, as "...the harder budget constraints politicians face, the more likely they should be to privatize government." (Lopez et al. 1997, p. 454).

The results of the Probit regressions using the 1990 data are reported below in table 3. None of the USACIR variables are included in this table, but including them did not alter the sign or magnitude of any of the other variables substantially. The signs and significance of these dummy variables are discussed next, along with the other results.

Rather than reporting the estimated Probit coefficients, which are difficult to interpret, the table above reports the marginal effect, that is, the change in the probability for an infinitesimal change in each independent, continuous variable and reports the discrete change in the probability for dummy variables. 
Table 5 Largest 200 U.S. cities, 1990

Dependent variable: mode (buy $=1$ ), marginal effects reported, standard errors in ( )

\begin{tabular}{|c|c|c|c|c|c|c|c|}
\hline pop65 & $\begin{array}{l}.10 \\
(.77)\end{array}$ & $\begin{array}{l}3.72 \\
(3.26)\end{array}$ & $\begin{array}{l}.83 \\
(.84)\end{array}$ & $\begin{array}{l}8.31^{* *} \\
(3.57)\end{array}$ & $\begin{array}{l}11.03^{* * *} \\
(3.65)\end{array}$ & $\begin{array}{l}11.97^{* * *} \\
(3.75)\end{array}$ & $\begin{array}{l}12.14^{* * *} \\
(3.71)\end{array}$ \\
\hline pop65sq & & $\begin{array}{l}-10.62 \\
(9.36)\end{array}$ & & $\begin{array}{l}-21.71^{* *} \\
(10.17)\end{array}$ & $\begin{array}{l}-28.72^{* * *} \\
(10.26)\end{array}$ & $\begin{array}{l}-30.70^{* * *} \\
(10.49)\end{array}$ & $\begin{array}{l}-33.46^{* * *} \\
(10.54)\end{array}$ \\
\hline $\log (\mathrm{pop})$ & & & $\begin{array}{l}-.17^{* * *} \\
(.05)\end{array}$ & $\begin{array}{l}-.18^{* * *} \\
(.05)\end{array}$ & $\begin{array}{l}-.17^{* * *} \\
(.06)\end{array}$ & $\begin{array}{l}-.18^{* * *} \\
(.06)\end{array}$ & $\begin{array}{l}-.18^{* * *} \\
(.06)\end{array}$ \\
\hline $\log$ (house_value) & & & $\begin{array}{l}.24^{* * *} \\
(.08)\end{array}$ & $\begin{array}{l}.26^{* * *} \\
(.08)\end{array}$ & $\begin{array}{l}.17^{*} \\
(.09)\end{array}$ & $\begin{array}{l}.16^{*} \\
(.09)\end{array}$ & $\begin{array}{l}.05 \\
(.10)\end{array}$ \\
\hline relative_wage_fire & & & & & & $\begin{array}{l}.34^{* *} \\
(.14)\end{array}$ & \\
\hline fire_union & & & & & & $\begin{array}{l}-.06 \\
(.07)\end{array}$ & \\
\hline relative_wage & & & & & $\begin{array}{l}.46^{* *} \\
(.22)\end{array}$ & & $\begin{array}{l}.42^{* *} \\
(.21)\end{array}$ \\
\hline union & & & & & $\begin{array}{l}.06 \\
(.12)\end{array}$ & & \\
\hline ideology & & & & & $\begin{array}{l}.99^{* * *} \\
(.38)\end{array}$ & $\begin{array}{l}.87^{* *} \\
(.38)\end{array}$ & $\begin{array}{l}.80^{* *} \\
(.38)\end{array}$ \\
\hline unemployment & & & & & $\begin{array}{l}-.02 \\
(.02)\end{array}$ & $\begin{array}{l}-.02 \\
(.02)\end{array}$ & $\begin{array}{l}-.008 \\
(.02)\end{array}$ \\
\hline yo/yy & & & & & & & $\begin{array}{l}-.23^{* *} \\
(.10)\end{array}$ \\
\hline Pseudo R2 & .00 & .01 & .10 & .12 & .18 & .16 & .20 \\
\hline LL & -130 & -129 & -117 & -114 & -104 & -103 & -101 \\
\hline
\end{tabular}

The estimated coefficient on population $>65$ is positive across all specifications. In the fourth specification, the coefficient is significant at the $5 \%$ level, and is significant at the $1 \%$ level in all subsequent specifications. The estimated coefficient on the square of population $>65$ is negative in all specifications, is significant at the $5 \%$ level in the fourth specification and at the $1 \%$ level in all subsequent specifications. The increasing significance of these estimates is primarily due to the increase in magnitude of the marginal effects in the later specifications, with the standard errors remaining about the same. Together, the positive marginal effect on population $>65$ and negative marginal effect on population $>65$ sq indicate the percent of the voting age population over the age of 65 has an inverted U-shape correlation with probability of outsourcing. The top of the inverted $\mathrm{U}$ is calculated to occur when population $>65$ 
is between 18 and 20\%. In the data, 62 cities have a population $>65$ that is larger than $18 \%$, and 22 cities have a population $>65$ that is greater than $20 \%$.

The results for population are negative and significant at the $1 \%$ level, with consistent marginal effect estimates and standard errors across all specifications. Although no prior sign was expected, this finding suggests that larger populations may be more strongly associated with smaller setup costs than thickness, or competitiveness, of the contractor market. The results for average housing value are positive across all specifications, but the marginal effects fall in magnitude in the later specifications, so much so that in the last specification this variable is no longer significant at the $10 \%$ level. It is possible that correlation between this variable and other variables, especially yo/yy, means its effect on outsourcing is diluted in the larger specifications. The theoretical model did not shed light on the expected sign; the positive correlation is consistent with contractors being more likely to operate in areas of high housing value, although it is unclear how average housing value also affects service level.

The coefficient on public-private wage ratio is positive, and this is the sign suggested by the model. The estimates are significant at the $5 \%$ level, and are of about the same magnitude in both specifications in which they appear. When the average wage of firefighters is used as the public wage, similar results obtain, namely, the marginal effect is positive (although of slightly smaller magnitude) and significant at the $5 \%$ level. The coefficient on ideology (proxied by percent Republican) is also of the expected sign (positive). The marginal effect varies in magnitude from .8 to 1 , and varies in significance from the $1 \%$ level to the $5 \%$ level.

Neither of the unionization variables, the percent of all city workers in unions or percent of firefighters in unions, is significant. Also, the coefficient on unemployment is not significant at the $10 \%$ level in any specification. The relative housing value variable is significant at the $5 \%$ level and of negative sign.

Finally, although the USACIR dummy variables are not reported in the above specifications, they were included in other specifications and are reported in the appendix. borrowing, which indicated that state law forbids short-term borrowing by cities, was significant at the $1 \%$ level, both when included with the rest of the other state law variables and when included separately. It was positive (marginal effect equals .25) which is in-line with the theory presented in Lopez-de-Silanes et al (1997). state assess, which indicated state property tax assessment is a state function, was also positive (marginal effect equals .16), consistent with theory, and this is significant at the $5 \%$ level in both specifications. No other variable was significant at the $5 \%$ level in either specification, nor at least the $10 \%$ in both specifications. Overall, the analysis indicates that for state laws, emergency ambulance service outsourcing is more responsive to budget constraint variables than to "clean government" variables, but not all budget constraint variables are important.

The same specifications in table 3 are repeated with 2000 data, and the results are reported below in table 4 . However as indicated above, not all of the same data was available, in particular those related to unionization, and the USACIR variables. 
Table 6 Largest 200 U.S. cities, 2000

Dependent variable: mode (buy $=1$ ), marginal effects reported, standard errors in ( )

$\begin{array}{llllllll}\text { pop65 } & -.06 & 6.15 & .10 & 14.87^{* *} & 17.33^{* *} & 23.01^{* * *} & 16.73^{* *} \\ & (1.01) & (6.85) & (1.06) & (7.35) & (7.50) & (8.40) & (7.68) \\ \text { pop65sq } & & -21.47 & & -50.80^{* *} & -58.39^{* *} & -75.69^{* * *} & -58.42^{* *} \\ & & (23.44) & & (25.02) & (25.51) & (28.29) & (26.08) \\ \log (\mathrm{pop}) & & & -.23^{* * *} & -.26^{* * *} & -.24^{* * *} & -.23^{* * *} & -.24^{* * *} \\ & & & (.06) & (.06) & (.06) & (.06) & (.06) \\ \log (\text { house_value) } & & & .06 & .08 & .04 & -.02 & -.06 \\ & & & (.07) & (.07) & (.08) & (.08) & (.09) \\ \text { relative_wage_fire } & & & & & .27^{* *} & \\ & & & & .27 & (.13) & \\ \text { relative_wage } & & & & (.18) & & .13 \\ \text { ideology } & & & & .005 & .004 & .006^{*} \\ & & & & & (.003) & (.003) & (.003) \\ \text { unemployment } & & & & & -.02 & -.06 & -.02 \\ & & & & & (.03) & (.04) & (.03) \\ \text { yo/yy } & & & & & & -.22^{* *}\end{array}$

\begin{tabular}{llllllll} 
Pseudo R2 & .00 & .003 & .07 & .09 & .11 & .11 & .12 \\
LL & -136 & -136 & -127 & -125 & -122 & -112 & -120 \\
\hline$* * *, * *$
\end{tabular}

${ }^{* * *},{ }^{* *}$ and ${ }^{*}$ denote significant at $1 \%, 5 \%$ and $10 \%$ level, respectively, with

appropriate test statistics

The results of analysis of the 2000 data largely confirm the findings of the 1990 with respect to population $>65$ and population $>65$ squared. The coefficient on population $>65$ is positive and varies in significant from $5 \%$ in the fourth specification to $1 \%$ in larger specifications. Similarly, the coefficient on population $>65$ squared is negative (as in 1990) and varies in significance from $5 \%$ to $1 \%$ in fourth column and later specifications, respectively. In this case, the top of the inverted $\mathrm{U}$ occurs between 14-16\%, somewhat earlier than in 1990. In the 2000 data, 115 cities have population $>65$ that is larger than $14 \%$, and 61 cities have population $>65$ larger than $16 \%$.

The marginal effect and significance of log population is very similar to 1990 in that it is positive and significant at the $1 \%$ level in all specifications. The coefficient on yo/yy remains negative and is still significant at the $5 \%$ level, as in 1990 . However there are a number of differences to report with the rest of the variables. Log of 
average housing value is not significant at the $10 \%$ level in any specification. Also, the coefficient on wage ratio, while still positive in all regressions, is no longer significant at the $10 \%$ level when the average wage of all public employees is used as the public wage. However when the average wage of firefighters is used as the public wage, the coefficient remains positive at the $5 \%$ level. This shows that taking into account the specific details of the institutional setting for ambulances is important.

Unemployment remains insignificant as in 1990. However ideology, while still positive, is not significant in 2000, except for being marginally significant in the final specification. However, the marginal effect is of substantially lower magnitude. There are several possible explanations for why these variables do not do as well of a job explaining ambulance outsourcing in the 2000 regression.

Although only conjecture, perhaps the most compelling reason is that urban sprawl has intensified over the decade, and so the variables that rely on countylevel measures do not do as well of a job of measuring the city characteristics they are meant to proxy. These county-level variables include percent Republican, private sector wage and unemployment.

Another possible reason has to do with the unobserved changes in the EMS industry. EMS is a much more recent service to be provided by local governments; a telling statistic is that even in 2000, several states indicated they had at least one funeral home providing EMS transport service (EMS Magazine, 2001); while this seems strange today, having hearses provide medical transport was a fairly common practice even as recently as a few decades ago (Poole, 1980). Given the potential changes over time, it is important to know whether data from both years should be pooled. The Chow-type test for Probit models (Greene, 2000) rejects the hypothesis that the coefficient vectors are the same in both periods at the $95 \%$ confidence level.

A final result may shed light on a different but related question; that is if, and how, cities with different forms of government respond to political incentives. The large majority of cities are of two main forms: council-manager or mayor-council. The first is analogous to a parliamentary form of government in that the elected council hires a manager to run the city, while the second is analogous to a presidential system of government in that the voters elect not only the council, but also the leader (the mayor).

Levin and Tadelis (2007, p. 12) conjecture, "...elected mayors may have motivations that are more explicitly political than appointed managers." They find that managers are somewhat more likely to outsource services, and this is true here as well. ${ }^{26}$ This notion can be captured through the theoretical model presented in this paper. If it is true that city managers do not care about politics, then it is reasonable to expect them to be social welfare maximizers. This means they should treat each $\phi^{j}$ as equal to one, and so although managers would still take into account the preferences of the elderly, they would be less sensitive to their concerns than would mayors.

\footnotetext{
${ }^{26}$ Results using a form of government dummy (council-manager $=0$, mayor-council=1) are not reported. The esimated marginal effect was negative, but was not significant.
} 
This story basically plays out in the 2000 data, although the author is hesitant to make too much of the result. In the 2000 data, the correlation on population $>$ 65 and its square is being driven by the mayor-council cities. When the sample is split by form of government, both forms exhibit the inverted U-shaped correlation, but it is only significant for mayoral cities. Pooling the samples does not lower the standard errors, although the Chow-type test for Probit models suggets both form of government samples should be pooled. In 1990, however, managerial cities did exhibit the inverted U-shaped correlation and it was significant and the $5 \%$ level, and pooling both types of cities lowered the standard errors. The Chow-type test indicates both form of government samples should also be pooled in 1990. While it is difficult to find the reason for the apparent change in behavior in managerial cities, and will have to be left for future work, this finding suggests that mayoral cities may be more responsive to the elderly as an interest group compared to managerial cities when it comes to emergency ambulances, and this seems to be a fairly recent trend.

\section{Conclusion}

This study has contributed towards the development of a political economy "make or buy" model by incorporating politicians, voters, elections and public good production technology into a common framework. This study has also suggested an alternative shape for the contracting cost curve, which better fits the results of the data, and also makes sense theoretically; namely, that while contracting costs may be convex, there may also be important fixed costs to contracting. Fixed costs are especially important because they may be related to the "political considerations" that feature prominently in many discussions of local public service outsourcing.

Overall, the transaction cost basis of the model is supported by the positive marginal effect on $w^{\mu} / w^{\beta}$. Although some variables were not significant, no significant variable contradicts the transaction cost basis of the model. The inverted U-shaped finding on the population $>65$ variables suggests two things. First, the presence of a significant correlation suggests interest group politics is an important consideration with emergency ambulance outsourcing. Second, the inverted U-shaped correlation is consistent with a convex contracting cost curve with fixed costs. Levin and Tadelis (2007) model the outsourcing problem with convex contracting cost curve without fixed costs; the empirical analysis here rejects this formulation. Although the convexity of the contracting cost curve is supported by the data, the addition of fixed costs are required to explain the findings here.

The convex contracting cost curve and positive fixed costs model yields the following interpretation: if a politician needs only to provide a low level of public service quality in order to maximize his electoral chances, then he will not find it worthwhile to incur the fixed costs associated with outsourcing (which may be thought of as costs associated with labor union strikes, although other interpretations are possible.) If the politician needs to provide a moderate level of service quality to maximize his 
probability of election, the cost savings allowed by outsourcing (that are associated with its more efficient production method) outweigh the fixed cost to contracting, and the variable costs to contracting are still not high. However, if a very high level of service quality is required to maximize the politician's electoral changes, the variable contracting costs (which may include specifying, monitoring and enforcing the contract) associated with outsourcing become increasingly important. With convex contracting costs, in-house production will again become the cost minimizing way to provide the service.

Future research should look at other settings beyond EMS; schools, recycling programs and public transportation projects are all areas of public policy where interest group politics are likely to be important. These areas would be good candidates to explore in the context of the model developed in this paper. Another direction to consider is to improve the understanding of appropriate empirical measures of the power of certain groups (the $\phi$ 's); this would shed light on an important dimension to intergenerational voter conflict. As this article demonstrates age-based interest group politics are important in other areas of public policy, beyond the often studied topic of social security and Medicare.

\section{Appendix}

\subsection{Derivation of $w_{\beta}<w_{\mu}$}

Levin and Tadelis (2007) derive the relationship $w_{\beta}<w_{\mu}$ by postulating: a utility function for the worker is equal to $w-c(e)+(T-t) \widehat{w}$, where $w$ is the wage the worker receives upon meeting his contractual obligations, $c(e)$ is the cost of exerting effort level $e, T$ is the amount of time in a day, $t$ is the amount of time the worker spends on the job and $\widehat{w}$ is the value of the worker's outside option. The worker can turn his time and effort into output according to the function $q=$ et.

The politician has two instruments by which to contract with the worker: a performance contract, which means the worker must meet the constraint $q>\bar{q}$, and an employment contract, where the worker must meet the constraint $t>\bar{t}$. Their proposition 1 shows why minimization on $w$ will never lead to both constraints binding at the same time. The worker's effort is unobservable to the politician; under an employment contract, they assume the worker has no incentive to expend effort greater than $\underline{e}$, but $\underline{e}>0$. Under a performance contract, on the other hand, the worker has an incentive to exert a higher level of effort. This high powered incentive is introduced with a performance contract by allowing the worker to leave the job whenever the job is finished (i.e. whenever $q \geq \bar{q}$ ). A worker under a performance contract will always be willing to accept a lower wage than a worker under an employment contract due to the former's ability to make intertemporal substitution. 
As a digression, it may be possible to extend the model presented in the main body of the present text by incorporating these public workers into the model. As of now they are exogenous as the workers are not differentiated from those that vote, pay taxes and consume the public good. Including public employees also represents a way to obtain fixed costs from externalities across services. Imagine an employee's outside option $\widehat{w}$ is a function of how secure public employees feel in their job, in the sense of not being laid-off. Imagine further the city produces two goods. If the city outsources production of the first good, then the workers who produce the second good modify their expectations of the probability they will get fired at their current city job upward. The equilibrium wage the city will have to be pay will then go up. Politicians do not make decisions about one service in isolation and this type of cost can be thought of as a fixed cost to having a service privatized.

\subsection{Derivation of equilibrium $g$}

Equation (10) $\frac{\partial E \pi_{A}}{\partial g^{\mu}}=\sum_{j=O}^{Y} \alpha^{j} \phi^{j} \frac{\partial U^{j}\left(g_{A}^{\mu}\right)}{\partial g_{A}^{\mu}}=0$

For the make case, $U^{j}\left(g^{\mu}\right)=\left(1-\frac{w^{\mu} g^{\mu}+s}{y}\right) y^{j}+\lambda^{j} \ln \left(g^{\mu}\right)$, and $\frac{\partial U^{j}\left(g_{A}^{\mu}\right)}{\partial g_{A}^{\mu}}=-\frac{w^{\mu} y^{j}}{y}+\frac{\lambda^{j}}{g^{\mu}}$ thus equation (10) can be rewritten as $\sum_{j=O}^{Y} \alpha^{j} \phi^{j}\left(\frac{\lambda^{j}}{g^{\mu}}-\frac{w^{\mu} y^{j}}{y}\right)=0$

Because there are two groups, $j=Y, O$

$$
\begin{aligned}
& \alpha^{O} \phi^{O}\left(\frac{\lambda^{O}}{g^{\mu}}-\frac{w^{\mu} y^{O}}{y}\right)+\alpha^{Y} \phi^{Y}\left(\frac{\lambda^{Y}}{g^{\mu}}-\frac{w^{\mu} y^{Y}}{y}\right)=0 \\
& ->\frac{\alpha^{O} \phi^{O} \lambda^{O}+\alpha^{Y} \phi^{Y} \lambda^{Y}}{g^{\mu}}=\frac{w^{\mu}\left(\alpha^{O} \phi^{O} y^{O}+w^{\mu} \alpha^{Y} \phi^{Y} y^{Y}\right)}{y} \\
& ->g^{\mu}=\frac{y\left(\alpha^{O} \phi^{O} \lambda^{O}+\alpha^{Y} \phi^{Y} \lambda^{Y}\right)}{w^{\mu}\left(\alpha^{O} \phi^{O} y^{O}+w^{\mu} \alpha^{Y} \phi^{Y} y^{Y}\right)}
\end{aligned}
$$

Multiplying both sides by $w^{\mu}$ yields equation (11).

Equation (12) is derived in a similar manner. For the buy case:

$$
\begin{aligned}
& U^{j}\left(g^{\beta}, \lambda^{j}, y^{j}, y, r, w^{\beta}\right)=\left(1-\frac{w^{\beta} g^{\beta}+d\left(g^{\beta}, r\right)}{y}\right) y^{j}+\lambda^{j} \ln \left(g^{\beta}\right) \text { and } \frac{\partial U^{j}\left(g_{A}^{\beta}\right)}{\partial g_{A}^{\beta}}=-\frac{\left(w^{\beta}+d_{g}\left(g^{\beta}, r\right)\right) y^{j}}{y}+ \\
& \frac{\lambda^{\beta}}{y}
\end{aligned}
$$

and so equation (10), for the cases $j=O, Y$, can be rewritten as

$$
\begin{aligned}
& \frac{\alpha^{O} \phi^{O} \lambda^{O}+\alpha^{Y} \phi^{Y} \lambda^{Y}}{g^{\beta}}=\frac{\left(\alpha^{O} \phi^{O} y^{O}+\alpha^{Y} \phi^{Y} y^{Y}\right)\left(w^{\beta}+d_{g}\left(g^{\beta}, r\right)\right)}{y} \\
& ->g^{\beta}\left(w^{\beta}+d_{g}\left(g^{\beta}, r\right)=\frac{y\left(\alpha^{O} \phi^{O} \lambda^{O}+\alpha^{Y} \phi^{Y} \lambda^{Y}\right)}{\left(\alpha^{O} \phi^{O} y^{O}+\alpha^{Y} \phi^{Y} y^{Y}\right)}\right.
\end{aligned}
$$

and this is equation (12). 


\subsection{Derivation of comparative statics}

The condition for both make and buy is...

$\left.g w_{\beta}+g d_{g}(g, r)\right)=\frac{y\left[\phi^{Y} \lambda^{Y}+\alpha^{O}\left(\phi^{O} \lambda^{O}-\phi^{Y} \lambda^{Y}\right)\right]}{\left[\phi^{Y} y^{Y}+\alpha^{O}\left(\phi^{O} y^{O}-\phi^{Y} y^{Y}\right)\right]}$

where $y=y^{Y}+\alpha^{O}\left(y^{O}-y^{Y}\right)$

Rewriting as $\frac{\left(y^{Y}+\alpha^{O} b\right)\left(\phi^{Y} \lambda^{Y}+\alpha^{O} a\right)}{\phi^{Y} y^{Y}+\alpha^{O} c}=\frac{\left(\phi^{Y} \lambda^{Y} y^{Y}+\alpha^{O} a y^{Y}+\alpha^{O} b \phi^{Y} \lambda^{Y}+\alpha^{O^{2}} a b\right)}{\phi^{Y} y^{Y}+\alpha^{O} c}=\Omega$

where $a=\left(\phi^{O} \lambda^{O}-\phi^{Y} \lambda^{Y}\right)$ and $b=\left(y^{O}-y^{Y}\right)$ and $c=\left(\phi^{O} y^{O}-\phi^{Y} y^{Y}\right)$

Comparative Static: $\alpha^{O}$

$$
\begin{aligned}
& \frac{\partial \Omega}{\partial \alpha^{O}}=\frac{a y^{Y}+b \phi^{Y} \lambda^{Y}+2 \alpha^{O} a b}{\phi^{Y} y^{Y}+\alpha^{O} c}+\frac{\left(\phi^{Y} \lambda^{Y} y^{Y}+\alpha^{O} a y^{Y}+\alpha^{O} b \phi^{Y} \lambda^{Y}+\alpha^{2}{ }^{2} a b\right) c}{\left(\phi^{Y} y^{Y}+\alpha^{O} c\right)^{2}} \\
& \Rightarrow \quad \frac{\partial \Omega}{\partial \alpha^{O}}>0 \text { if } a y^{Y}+b \phi^{Y} \lambda^{Y}+2 \alpha^{O} a b>-\Omega c \\
& \Rightarrow \quad y^{Y} a+\Omega c>\left(y^{Y}-y^{O}\right)\left(\phi^{Y} \lambda^{Y}+2 \alpha^{O} a\right)
\end{aligned}
$$

If $\lambda^{O}>\lambda^{Y}, \phi^{O}>\phi^{Y}$ and $y^{O}>y^{Y}$ then the inequality holds. However if $\lambda^{O}>\lambda^{Y}$, $\phi^{O}>\phi^{Y}$ but $y^{O}<y^{Y}$ then the term on the left hand side is still positive as long as $\phi^{O} y^{O}-\phi^{Y} y^{Y} \geq 0$ and the equality will be true whenever the difference between $y^{Y}-y^{O}$ is small, and the difference between $\phi^{O} \lambda^{O}-\phi^{Y} \lambda^{Y}$ is large. Thus, in a nutshell, as long as $\lambda^{O}>\lambda^{Y}, \phi^{O}>\phi^{Y}$ are true, then the comparative static will still be positive as long as $y^{O}$ is not that much less than $y^{Y}$.

For example, consider the case when $y^{O}=0$. The $\mathrm{CS}$ is positive when $a\left(1-2 \alpha^{O}\right)>$ $\phi^{Y}\left(\lambda^{Y}+\Omega\right)$ which holds when $\phi^{Y}$ is small and when $\alpha^{O}$ is not too big; in the data used here, no city had a percent of elderly voters near .5 .

Comparative Static: $\lambda^{O}$

$$
\begin{aligned}
& \Omega=\frac{y\left[\phi^{Y} \lambda^{Y}+\alpha^{O}\left(\phi^{O} \lambda^{O}-\phi^{Y} \lambda^{Y}\right)\right]}{\left[\phi^{Y} y^{Y}+\alpha^{O}\left(\phi^{O} y^{O}-\phi^{Y} y^{Y}\right)\right]} \\
& \frac{\partial \Omega}{\partial \lambda^{O}}=\frac{\alpha^{O} \phi^{O} y}{\phi^{Y} y^{Y}+\alpha^{O}\left(\phi^{O} y^{O}-\phi^{Y} y^{Y}\right)}
\end{aligned}
$$

Comparative Static: $y^{O}$

$$
\Omega=\frac{\left[y^{Y}+\alpha^{O}\left(y^{O}-y^{Y}\right)\right]\left[\phi^{Y} \lambda^{Y}+\alpha^{O}\left(\phi^{O} \lambda^{O}-\phi^{Y} \lambda^{Y}\right)\right]}{\left[\phi^{Y} y^{Y}+\alpha^{O}\left(\phi^{O} y^{O}-\phi^{Y} y^{Y}\right)\right]}
$$




$$
\frac{\partial \Omega}{\partial y^{O}}=\frac{\alpha^{O}\left[\phi^{Y} \lambda^{Y}+\alpha^{O}\left(\phi^{O} \lambda^{O}-\phi^{Y} \lambda^{Y}\right)\right]}{\left[\phi^{Y} y^{Y}+\alpha^{O}\left(\phi^{O} y^{O}-\phi^{Y} y^{Y}\right)\right]}-\frac{\left[y^{Y}+\alpha^{O}\left(y^{O}-y^{Y}\right)\right]\left[\phi^{Y} \lambda^{Y}+\alpha^{O}\left(\phi^{O} \lambda^{O}-\phi^{Y} \lambda^{Y}\right)\right] \alpha^{O} \phi^{O}}{\left[\phi^{Y} y^{Y}+\alpha^{O}\left(\phi^{O} y^{O}-\phi^{Y} y^{Y}\right)\right]^{2}}
$$

This is positive if

$$
\begin{aligned}
& \alpha^{O}>\frac{\left[y^{Y}+\alpha^{O}\left(y^{O}-y^{Y}\right)\right] \alpha^{O} \phi^{O}}{\left[\phi^{Y} y^{Y}+\alpha^{O}\left(\phi^{O} y^{O}-\phi^{Y} y^{Y}\right)\right]}--> \\
& {\left[\phi^{Y} y^{Y}+\alpha^{O}\left(\phi^{O} y^{O}-\phi^{Y} y^{Y}\right)\right]>\left[y^{Y}+\alpha^{O}\left(y^{O}-y^{Y}\right)\right] \phi^{O}-->} \\
& \alpha^{Y} \phi^{Y} y^{Y}+\alpha^{O} \phi^{O} y^{O}>\alpha^{Y} y^{Y} \phi^{O}+\alpha^{O} \phi^{O} y^{O}--> \\
& \phi^{Y}>\phi^{O}
\end{aligned}
$$

Comparative Static: $\phi^{O}$

$$
\begin{aligned}
& \Omega=\frac{\left[y^{Y}+\alpha^{O}\left(y^{O}-y^{Y}\right)\right]\left[\phi^{Y} \lambda^{Y}+\alpha^{O}\left(\phi^{O} \lambda^{O}-\phi^{Y} \lambda^{Y}\right)\right]}{\left[\phi^{Y} y^{Y}+\alpha^{O}\left(\phi^{O} y^{O}-\phi^{Y} y^{Y}\right)\right]} \\
& \frac{\partial \Omega}{\partial \phi^{O}}=\frac{\left[y^{Y}+\alpha^{O}\left(y^{O}-y^{Y}\right)\right] \alpha^{O} \lambda^{O}}{\left[\phi^{Y} y^{Y}+\alpha^{O}\left(\phi^{O} y^{O}-\phi^{Y} y^{Y}\right)\right]}-\frac{\left[y^{Y}+\alpha^{O}\left(y^{O}-y^{Y}\right)\right]\left[\phi^{Y} \lambda^{Y}+\alpha^{O}\left(\phi^{O} \lambda^{O}-\phi^{Y} \lambda^{Y}\right)\right] \alpha^{O} y^{O}}{\left[\phi^{Y} y^{Y}+\alpha^{O}\left(\phi^{O} y^{O}-\phi^{Y} y^{Y}\right)\right]^{2}}
\end{aligned}
$$

is positive if $\quad \frac{\left[y^{Y}+\alpha^{O}\left(y^{O}-y^{Y}\right)\right] \alpha^{O} \lambda^{O}}{\left[\phi^{Y} y^{Y}+\alpha^{O}\left(\phi^{O} y^{O}-\phi^{Y} y^{Y}\right)\right]}>\frac{\left[y^{Y}+\alpha^{O}\left(y^{O}-y^{Y}\right)\right]\left[\phi^{Y} \lambda^{Y}+\alpha^{O}\left(\phi^{O} \lambda^{O}-\phi^{Y} \lambda^{Y}\right)\right] \alpha^{O} y^{O}}{\left[\phi^{Y} y^{Y}+\alpha^{O}\left(\phi^{O} y^{O}-\phi^{Y} y^{Y}\right)\right]^{2}}$

$$
\begin{aligned}
& \frac{\alpha^{O} \lambda^{O}}{\alpha^{O} y^{O}}>\frac{\left[\phi^{Y} \lambda^{Y}+\alpha^{O}\left(\phi^{O} \lambda^{O}-\phi^{Y} \lambda^{Y}\right)\right]}{\left[\phi^{Y} y^{Y}+\alpha^{O}\left(\phi^{O} y^{O}-\phi^{Y} y^{Y}\right)\right]} \\
& \lambda^{O}\left[\phi^{Y} y^{Y}+\alpha^{O}\left(\phi^{O} y^{O}-\phi^{Y} y^{Y}\right)\right]>y^{O}\left[\phi^{Y} \lambda^{Y}+\alpha^{O}\left(\phi^{O} \lambda^{O}-\phi^{Y} \lambda^{Y}\right)\right] \\
& ->\quad \lambda^{O} \alpha^{Y} \phi^{Y} y^{Y}+\lambda^{O} \alpha^{O} \phi^{O} y^{O}>\lambda^{Y} \alpha^{Y} \phi^{Y} y^{O}+\lambda^{O} \alpha^{O} \phi^{O} y^{O} \\
& ->\quad \lambda^{O} \alpha^{Y} \phi^{Y} y^{Y}>\lambda^{Y} \alpha^{Y} \phi^{Y} y^{O}-->\quad \lambda^{O} y^{Y}>\lambda^{Y} y^{O} \\
& ->\quad \frac{\lambda^{O}}{y^{O}}>\frac{\lambda^{Y}}{y^{Y}}
\end{aligned}
$$




\subsection{Data Appendix: JEMS Data Set}

Data for the JEMS data set comes from annual surveys conducted by the Journal of Emergency Medical Service. They survey the 200 largest cities in the U.S. A typical entry includes the following information: the name of the city and a list of every provider serving that community. In addition, next to the name of each provider, it reports the type of provider (categories include one through nine below) and whether it provides transport versus first responding service to the community (or both).

Respondents to the JEMS survey had a list of nine choices to choose from (JEMS 1990) need to use 1991 and include page number:

- (1 - Fire Department) Fire-department-based responders trained as both firefighters and EMTs, using the either the same personnel to perform both fire protection and EMS, or different personnel to provide both services.

- (2 - 3rd service, municipal) Funded and operated by municipal government (utilizing local government employees) and not administered by the fire or police department

- (3 - 3rd service, county) Funded and operated by the county government (using county government employees) and not administered by a law-enforement or fire-protection agency

- (4 - Public Trust) A quasi-governmental entity that operates an ambulance system using its own employees.

- (5 - Hospital-Based) A hospital owned and operated ambulance service

- (6 - Private) A privately owned company or corporation engaged in the provision of medical transportation

- (7 - Public Utility Model) A regulated-monopoly ambulance system that selects the exclusive provider based on a competitive procurement process. These systems are usually single-tiered, providing emergency and non-emergency service with an all-advanced-life-saving fleet. Commonly, a quasi-governmental entity supervises the contract and performs billing/collection services

- (8 - Volunteer) A volunteer agency provides EMS

- (9 - Police) Funded and operated by municipal government (utilizing local government employees) and administered by the police department 
Table 7 Cities use of EMS transport delivery mode, by year $\quad 1990 \quad 2000$

$\begin{array}{rrr}\text { Fire department } & 54 & 63 \\ \text { Private } & 52 & 61 \\ \text { Third service (municipal) } & 15 & 10 \\ \text { Multiple private } & 13 & 4 \\ \text { Third service (county) } & 8 & 8 \\ \text { Hospital } & 8 & 7 \\ \text { Fire department w/ contractor } & 5 & 5 \\ \text { Public utility model } & 5 & 7 \\ \text { Public trust } & 3 & 0 \\ \text { Multiple hospital } & 2 & 0 \\ \text { Third service (county) w/ contractor } & 1 & 2 \\ \text { Volunteer } & 1 & 1 \\ \text { Volunteer w/ private } & 1 & 0 \\ \text { Police department } & 1 & 1\end{array}$

note: data from both years were pooled to include only cities that appear in both years

Items 1-2 and 9 were coded as "make" with the remaining six coded as "buy," 


\subsection{Classifying Cities as "mayor-council" versus "council man- ager"}

Form of government data comes from two sources: For 1992, Census of Governments, Organization Phase, and for 2007 was provided to the author by ICMA. When these data indicated a city switched form of government, the following rule was used to ensure accuracy of form of government data:

1. Treat ICMA data as correct, and count "commission" forms as "mayor-council"

2. Treat Census data as correct when it classifies a city as "council-manager"

3. Be suspicious of Census data that classifies a city as "mayor-council"; except when it can be verified through Google searches, as in the case of Sioux Falls, Chattanooga and El Paso. Label these cities as "council-manager."

Google searches, telephone calls and researching city charters shows these rules are consistent with the available evidence. Using these rules makes sense for the following reasons. 1.) Knowing form of government data is ICMA's core competency. Also, city webpages verified all the ICMA categorizations were correct, except those of "commission." However, in these cases, city webpages (as well as telephone calls to city officials) revealed all switchers labeled as "commission" form were actually "mayorcouncil" form. 2.) "mayor-council" cities are more difficult to correctly classify than "council-manager" 3.) Due to the difference between "weak mayors" and "strong mayors" it makes sense to classify a switcher Census data labels as "mayor-council" as "council-manager" especially because many Google searches and telephone calls verify that the Census data is often wrong on these classifications. However, Google searches reveal that the Census is sometimes right, so it make sense to keep the classification the same in these cases. These three cities were verified to switch from mayor council to council manager. The rest of the cities could not be verified as having switched and in fact several were verified to not have switched with the help of ICMA employee Martha Perego, who was of great assistance and accessed the ICMA's city charter database on the author's behalf. For these cities, "council-manager" is used as form of government. The likely reason for why most switchers listed as mayor-council were incorrect is the difference between a "weak mayor" and "strong mayor".

The problem with this technique is that it will not catch cities that switched from council-manager to mayor-council; that is, some cities could still be incorrectly classified as mayor-council in 1987 even though they were council-manager cities, as they would not have shown up as switchers. However, as few cities switch form of government from year to year, this problem is not likely to be large. 


\subsection{State Laws and Outsourcing}

Table 8 below presents results of the baseline regressions with the USACIR state law dummies. The state law dummies are included separately and together as it is not clear that the presence of one law weakens the effects of other laws.

Table 8 Largest 200 U.S. cities, 1990

\begin{tabular}{|c|c|c|c|c|c|c|c|c|c|c|}
\hline \multirow[t]{2}{*}{ pop 65} & $8.205^{* *}$ & $7.182^{* *}$ & $8.079^{* *}$ & $8.569^{* *}$ & $8.422^{* *}$ & $9.134^{* *}$ & $8.461^{* *}$ & $8.781^{* *}$ & $8.491^{* *}$ & $8.311^{* *}$ \\
\hline & $(3.66)$ & $(3.53)$ & $(3.54)$ & $(3.66)$ & $(3.58)$ & $(3.63)$ & $(3.56)$ & $(3.61)$ & $(3.58)$ & $(3.57)$ \\
\hline \multirow[t]{2}{*}{ pop $65 \mathrm{sq}$} & $-21.09^{* *}$ & $-18.71^{*}$ & $-20.66^{* *}$ & $-22.53^{* *}$ & $-21.95^{* *}$ & $-25.02^{* *}$ & $-22.25^{* *}$ & $-22.83^{* *}$ & $-21.98^{* *}$ & $-21.71^{* *}$ \\
\hline & $(10.6)$ & $(10.0)$ & $(10.1)$ & $(10.6)$ & $(10.2)$ & $(10.4)$ & $(10.1)$ & $(10.3)$ & $(10.2)$ & $(10.2)$ \\
\hline \multirow[t]{2}{*}{$\log (p o p)$} & $-0.172^{* * *}$ & $-0.180^{* * *}$ & $-0.171^{* * *}$ & $-0.175^{* * *}$ & $-0.175^{* * *}$ & $-0.176^{* * *}$ & $-0.173^{* * *}$ & $-0.174^{* * *}$ & $-0.173^{* * *}$ & $-0.182^{* * *}$ \\
\hline & $(0.051)$ & $(0.050)$ & $(0.051)$ & $(0.051)$ & $(0.051)$ & $(0.052)$ & $(0.051)$ & $(0.051)$ & $(0.051)$ & $(0.051)$ \\
\hline \multirow[t]{2}{*}{$\log$ (hvalue) } & $0.266^{* * *}$ & $0.279^{* * *}$ & $0.274^{* * *}$ & $0.267^{* * *}$ & $0.268^{* * *}$ & $0.266^{* * *}$ & $0.242^{* * *}$ & $0.269^{* * *}$ & $0.275^{* * *}$ & $0.261^{* * *}$ \\
\hline & $(0.077)$ & $(0.077)$ & $(0.077)$ & $(0.078)$ & $(0.078)$ & $(0.077)$ & $(0.081)$ & $(0.077)$ & $(0.080)$ & $(0.077)$ \\
\hline \multirow[t]{2}{*}{ debt limit } & 0.0323 & & & & & & & & & 0.110 \\
\hline & $(0.11)$ & & & & & & & & & $(0.14)$ \\
\hline \multirow[t]{2}{*}{ borrowing } & & $0.260^{* * *}$ & & & & & & & & $0.253^{* * *}$ \\
\hline & & $(0.076)$ & & & & & & & & $(0.080)$ \\
\hline \multirow[t]{2}{*}{ standards } & & & $-0.146^{*}$ & & & & & & & -0.133 \\
\hline & & & $(0.077)$ & & & & & & & $(0.085)$ \\
\hline \multirow[t]{2}{*}{ take over } & & & & 0.0194 & & & & & & 0.0665 \\
\hline & & & & $(0.12)$ & & & & & & $(0.14)$ \\
\hline \multirow[t]{2}{*}{ balanced budget } & & & & & 0.0269 & & & & & -0.0251 \\
\hline & & & & & $(0.13)$ & & & & & $(0.18)$ \\
\hline \multirow[t]{2}{*}{ state assess } & & & & & & $0.159^{* *}$ & & & & $0.187^{* *}$ \\
\hline & & & & & & $(0.080)$ & & & & $(0.093)$ \\
\hline \multirow[t]{2}{*}{ merit } & & & & & & & -0.0691 & & & -0.0646 \\
\hline & & & & & & & $(0.074)$ & & & $(0.081)$ \\
\hline \multirow[t]{2}{*}{ no strike } & & & & & & & & -0.156 & & -0.168 \\
\hline & & & & & & & & $(0.20)$ & & $(0.22)$ \\
\hline \multirow[t]{2}{*}{ no pol activity } & & & & & & & & & -0.0298 & -0.0362 \\
\hline & & & & & & & & & $(0.073)$ & $(0.083)$ \\
\hline
\end{tabular}

Pseudo R2

LL

$* * *, * *$ and $*$ denote significant at $1 \%, 5 \%$ and $10 \%$ level, respectively, with

appropriate test statistics 


\section{References}

1. Bajari and Tadelis "Incentives Versus Transaction Costs: A Theory of Procurement Contracts" The RAND Journal of Economics, 2001, 32(3) pp. 387-407.

2. Boycko, Maxim Boycko; Andrei Shleifer; Robert W. Vishny. "A Theory of Privatization" The Economic Journal, 1996, 106(435) pp. 309-319.

3. Brown, Trevor; Potoski, Matthew. "Managing Contract Performance: A Transaction Costs Approach" Journal of Policy Analysis and Management, 2003, $22(2)$, pp. $275-297$

4. Brunner and Balsdon "Intergenerational Conflict and the Political Economy of School Spending" Journal of Urban Economics, V 56 issue 2, 2004

5. Campbell, Andrea Louise. How Policies Make Citizens: Senior Citizen Activism and the American Welfare State. Princeton University Press, 2003

6. Davis, Robert "Many Lives are Lost Across USA Because Emergency Services Fail" USA Today $7 / 28 / 2006$

7. Downing, Amy; Wilson, Richard. "Older People's Use of Accident and Emergency Services." Age and Ageing, 2005, 34(1), pp.24-30

8. Gerber, Elisabeth, Hall, Christianne, and Hines, James. "Privatization: Issues in Local and State Service Provision." Center for Local, State, and Urban Policy, University of Michigan, Policy Report 1, 2004

9. Gerson, LW; Skvarch, L. "Emergency Medical Service Utilization by the Elderly" Annals of Emergency Medicine, 1982, 11(11), pp. 610-2

10. Hart, Oliver; Shleifer, Andrei; Vishny, Robert. "The Proper Scope of Government: Theory and Applications to Prisons." Quarterly Journal of Economics, 1997, 112(4) p. 1127

11. Hirsch, Werner. "Contracting Out by Urban Governments: A Review" Urban Affairs Review, 30(3), pp. 458-472

12. ICPSR 1988, Election Returns by Counties

13. Journal of Emergency Medical Service, "200 City Survey" 1991 and 2001

14. Kotlikoff, Laurence J. and Burns, Scott. The Coming Generational Storm MIT Press, 2004, Cambridge, MA

15. Laffont and Tirole $A$ Theory of Incentives in Procurement and Regulation Massachusetts Institute of Technology, 1993, Cambridge, MA 
16. Levin, Jonathon; Tadelis, Steven. "Contracting for Government Services: Theory and Evidence from U.S. Cities" mimeo, 2007, UC Berkeley

17. Lopez-de-Silanes, Shleifer and Vishny. "Privatization in the United States." Bell Journal of Economics, 1997, 28(3), pp. 447.

18. Mueller, Dennis. Public Choice III Cambridge University Press, 2003, Cambridge, UK

19. Persson and Tabellini Political Economics: Explaning Economic Policy,Massachusetts Institute of Technology, 2000, Cambridge, MA.

20. Pew Research Center. Regular Voters, Intermittent Voters, and Those Who Don't. Who Votes, Who Doesn't, and Why. released 10/18/2006

21. Poterba, James. "Demographic Change, Intergenerational Linkages, and Public Education" American Economic Review, 1996 (Papers and Proceedings) 88(2) pp. $315-320$

22. Tirole, Jean "The Internal Organization of Government" Oxford Economic Papers, 1994, 46, pp. 1. 